\title{
Introduction: A Brief History of Antichthon to Mark its 50th Anniversary
}

In the first half of the 1960s there were several groups putting forward proposals to establish a wider-based, academic organisation to promote Classics and Ancient World Studies. There had been in existence for many years state Classical Associations, based on the model of, and affiliated to, the U.K. Classical Association, but these were, and still are, comprised of a different range of members - academics, schoolteachers, and interested persons from the general public - and, being located primarily in the state capital cities, they had a local orientation. What the new groups were looking for was a more 'professional' organisation which would be attractive to academics, and in particular they focussed on the desire to set up a national academic journal to promote their disciplines of Classics and Ancient World Studies.

To some extent university Classics staff had been offered support from a body called AULLA ('Australasian Universities Language and Literature Association'), which had been formed in 1957 and which, as its name implied, covered both Australia and New Zealand. AULLA met in Congress every 18 months to two years in either Australia or New Zealand. The Congresses regularly had a Classics Section, with a local convenor who arranged for the giving of papers by university staff offering them. AULLA also published a journal, AUMLA, which arose out of the Australasian Universities Modern Languages Association (the forerunner of AULLA); the name implies its orientation, and the journal was not seen as an entirely congenial location for articles on Greek and Roman topics, though such did appear from time to time.

Ancient Historians had been partially catered for by the Australian and New Zealand Association for the Advancement of Science (ANZAAS). It was a more powerful organisation - it did have the word 'Science' in it, after all - because it had the ear of government. It met in Congress every year or so at a host university; occasionally there would be a section for Archaeology (mainly Australian) or for Ancient World Studies, but it would depend on someone from the host university taking on the role of organising such a section. There was no publication to which staff in universities could submit articles, though abstracts of papers presented at ANZAAS Congresses could be collectively published afterwards.

One of the groups which met in the 1960s to create a new organisation was convened on the initiative of the enthusiastic but eccentric Godfrey Tanner, from Classics in the (then) University College of Newcastle. Under his guidance an organisation called 'The N.S.W and A.C.T. Joint Committee' 
(in reality a combination of the Classical Associations of N.S.W. and of the A.C.T.) convened the popular Morpeth Summer Conferences, which were attended by university staff and schoolteachers. Tanner proposed an 'Australian Classical Federation', with a wide-ranging membership. A series of meetings in Sydney in the second half of 1962 led to the setting up of a provisional organisation, with a provisional president and secretary, an interim executive committee, and a draft constitution. The whole proposal was to be formally discussed at the Morpeth Conference planned for January 1963.

There had been a lot of correspondence, especially from other states, which suggested that the proposal and interim organisation had been put together too hastily and without sufficient consultation, and the project lapsed. But seeds had been planted, since part of Tanner's proposal was for the setting up of a journal, with the provisional title of Dodona. He was a persuasive fund-raiser and had collected an amount of $£ 300$ to help with the journal's cost (a not inconsiderable sum in those days, as some figures below will suggest).

Another group, convened by Edwin Judge (History, University of Sydney) and supported by the energetic Robert Dyer (Classics, The Australian National University), Judy Birmingham (Archaeology, University of Sydney), and Alf French (Classics, University of Adelaide), had a legendary meeting at the end of 1964 around the 'dining room table' of Edwin Judge's run-down Strathfield mansion. Their proposal was for the establishment of an 'Association for Studies in Ancient Society' (ASAS), with the aim of setting up a journal. A questionnaire was sent out in January 1965 to staff in Australian and New Zealand universities to gauge support for joining such an association and for contributing to such a journal.

To these two 'movements' was added a third initiative, aimed at creating a journal to cover both Greek and Latin language and literature and Ancient History. A group of classicists met in Sydney in June 1965, consisting of eight professors (the 'god professor' heads of various departments) and one other, and representing six universities (out of the ten in existence in Australia at that time with Classics or Classics-related departments). As recorded in Professor Richard Johnson's notes on this meeting, 'the sense of the meeting was that we should move towards the formation of a single body, embracing all those with special interests in Greece and Rome, in close association ... with AULLA, but formally independent of it.'

By now the ASAS proponents had called a meeting in Canberra for 14th August 1965, since some 60 scholars had expressed an interest in joining their proposed association, and 20 had offered articles for the planned journal. The agenda for this meeting was then combined with elements of the summary written by Richard Johnson of the meeting held in June, and the August meeting was actually chaired by him. The meeting reached certain agreements: the most pressing need was the creation of a general association of scholars, while Classics should remain within, or at least be affiliated to, AULLA. 
The meeting in Canberra in August was attended by 18 persons. Among other things, it resolved, 15 votes to 1 , that a small committee be appointed to draft proposals for the formation of an association of university teachers of Studies of the Ancient World (the latter being an amendment for 'Classical Studies'); that membership be open equally to scholars from Australia and New Zealand (carried unanimously); and that the drafting committee should consider the possibility of publishing a journal (carried 10 votes to 4). The drafting committee was made up of K.L. McKay (The Australian National University, convenor), E.A. Judge, J.J. Nicholls, and W. Ritchie (the latter three all from the University of Sydney).

As convenor, Ken McKay was assiduous in sending out a series of questionnaires devised by the drafting committee, which met in Sydney on a number of occasions, and meticulous in compiling the statistics from all the variations in the replies from university departments. By late August 1965 a draft constitution had been drawn up. A raft of seven names was suggested for the new association; in the end 'The Australian Society for Classical Studies' was chosen (because the New Zealanders by this stage had opted out of any joint association and were moving to form their own), ahead of the alternative 'Australian Universities Classical Association'.

A plethora of names for a journal had been put forward; an original list of 16 had been whittled down to nine (at that point Antichthon was not the favourite). Ken McKay's questionnaire of 26th November offered a choice of two: 'Australian Journal of Classical Studies' and Antichthon (the former was preferred by almost two votes to one). Because discussions were ongoing for some sort of New Zealand representation on the journal's editorial board, the shorter (and less cumbersome) one-word title was preferred, and confirmed in a subsequent postal ballot by 44 votes to 13 . The final draft constitution was circulated on 18th February 1966 and a postal vote undertaken, which created the new Society, with 62 foundation members.

A postal election was conducted in March and April to fill the various positions listed in the constitution. The results were as follows: President: Emer. Prof. A.D. Trendall; Vice President: Professor J.H. Bishop; Secretary: K.L. McKay; Treasurer: R.K. Sinclair; Editors: E.A. Judge and Professor W. Ritchie; plus one representative from each of the ten university departments teaching Classics or Classics-related subjects.

These elected persons constituted the ASCS Executive Committee; steps were being taken for the publication of Antichthon; and the first General Meeting of ASCS was being planned for August 1967 in conjunction with the Classics Section of the AULLA Congress to be held in Sydney at that time.

An indicator of the goodwill of scholars in classical studies could be seen in the generosity of two of the 'rival bidders': Godfrey Tanner offered to donate the funds he had raised for Dodona to assist with the publication of the first volume of Antichthon, and Edwin Judge agreed to stand for election as one of the inaugural editors of the new journal.

Between its establishment in February 1966 and its first General Meeting in August 1967, the business of the new Society was conducted by 
its Executive Committee, which met four times in Sydney. A membership subscription of $\$ 3.00$ ( $\$ 2.50$ of which was set aside for the journal) was set, raised to $\$ 4.00$ the following year. As to be expected, much of the Committee's time was taken up with discussing arrangements for publishing the journal. An earlier survey had established that the scope of the journal should be general, along the lines of, say, Classical Quarterly. Now the search was on to find a printer and to raise the funds. A number of printeries both in Australia and overseas were approached to provide quotations, but there were initial difficulties, the ability to print Classical Greek being one of them. Eventually Sydney University Press agreed to be the publisher, underwriting the first four volumes, with Griffin Press of Adelaide to do the actual printing. The foundation editors, Judge and Ritchie, moved ahead with the task of receiving articles and determining acceptance, and in mid-1968 the first volume (for 1967) containing ten articles appeared.

In following years the journal was printed by a number of companies until it settled at the University of New England Publishing Unit for 18 years from 1976, then Macquarie Lighthouse Press from 1998 to 2008, and McPhersons for Volumes 43-48. Then came a major recognition: Cambridge University Press asked the Society if it was willing for Antichthon to be added to its stable of prestigious international journals. This 'feather-in-the-cap' acknowledgement of the journal's already high standing commenced with CUP's publication of Vol. 49 for 2015.

Antichthon was envisaged to be, and still remains, an annual publication, but it has increased in size, from around 96 pages at the beginning to an average of 140 pages for the last ten issues. In 2006 thematic or special issues were introduced, and three of these have appeared so far (Vols 40, 43 and 47). In the first 20 to 30 years, it was a struggle to get the volumes out on time, or even close to time. As editors, Elizabeth Minchin (2004-2014) and Peter Davis (2004-2012), were particularly successful in solving this problem, and there were no less than eight occasions on their watch when the journal came out suo anno ('in its own year') - a truly remarkable achievement. The first volume published by CUP was available on line and the hard copy printed 'in its own year'; there was a problem with the distribution of the hard copies and they were not posted out until January 2016.

Careful supervision and prudent investment by the initial Treasurer, Bob Sinclair, and then the longest-serving Treasurer, Alan James, ensured financial security, and this success was aided by a steady increase in the number of members. By the 1980s, as the number of Classics departments in Australian universities had increased to twelve, membership had grown to around 150, and by the late 1990s it was just below 200. There were continued increases after that, not least the addition of some $70 \mathrm{New}$ Zealand colleagues, who after negotiations in 2003-4 agreed to amalgamate, leading to a change of name to 'The Australasian Society for Classical Studies' (requiring fortunately no change to the Society's 
acronym ASCS). By 2013 membership had reached just under 500, many of them postgraduate students, who were recognised as a specific category of membership in a new constitution drawn up in 2011.

The second tenure of the secretaryship by Bruce Marshall (2003-2013) saw a large expansion in new schemes for spending ASCS's money inviting keynote speakers to the annual conferences, supporting other conferences and seminars, providing grants to small departments and student conference travel subsidies, allocating \$2000 (now \$3000) a year for an annual 'early career award', and setting up prizes for various competitions. The total expenditure between 2003 and the present comes to well over $\$ 120,000$. This does not include the regular expenditure on the printing and distribution of the Society's journal, which cost around $\$ 10,000$ each year, on donations such as the fund for restoring the Logie Collection, the APA Foundation and the Institute of Classical Studies Library in London, on some of the administrative costs of conducting the annual conferences, on the bi-annual Newsletter, and on the general running of the Society's affairs.

After 50 years the Society is a thriving organisation due to those members who, over the years, have given voluntarily of their time to assist in organising and managing the Society's affairs and activities. It has become the peak professional body for academics and students of Classics and Ancient History, able to speak on behalf of its members to individual universities and even to government on occasion. The two core activities for which ASCS was founded - the publishing of a journal and the holding of a general meeting and conference - have been maintained and advanced: the journal now receives deservedly high international recognition, while the conferences, now held annually, attract enthusiastic scholars and students from across Australia and New Zealand and from overseas. The Society's stated aim of advancing the study of ancient Greece and Rome and related fields has been upheld with the strong expansion of its membership and activities and its expenditure on them. 


\section{ASCS OFFICEHOLDERS 1966-2016}

PRESIDENTS:

A. Dale Trendall 1966-1967

Harold A.K. Hunt 1967

A. John Dunston 1969

H. David Rankin 1970

Kenneth L. McKay 1971-1972

John R. Trevaskis 1973

Kenneth H. Waters 1974

John H. Bishop 1975

Graeme W. Clarke 1976-1979

George H. Gellie 1980

Paul R.C. Weaver 1981-1982

Kenneth J. McKay 1983-1984

Alfred French 1985-1986

Beryl Rawson 1987-1988

Robert K. Sinclair 1989-1990

R. Godfrey Tanner 1991-1993

Douglas H. Kelly 1994-1998

Kevin H. Lee 1999-2001

Gregory H.R. Horsley 2002-2005

John Penwill 2006-2008

John F. Davidson 2009-2011

Ronald T. Ridley 2012-2015

Anne Mackay 2015-present

SeCRetaries:

Kenneth L. McKay 1966-1969

Alan S. Henry 1970-1972

Jack R. Ellis 1973-1977

Bruce A. Marshall 1978-1987

Roger A. Pitcher 1988-2002

Bruce A. Marshall AM 2003-2013

Kathryn E. Welch 2013-present

TREASURERS:

Robert K. Sinclair 1966-1973

Alan W. James 1974-1995 (22 years)

James I. McDonald 1996-1997

Royce William Dolley 1998-present

EDITORS OF ANTICHTHON:

Edwin A. Judge and William Ritchie 1967-1972

E.A. Judge and Kenneth J. McKay 1973

K.J. McKay and Paul R.C. Weaver 1974-1982 
K.J. McKay and Raoul Mortley 1983-1984

R. Mortley and Gregory R. Stanton 1985-1989

Robert J. Baker and G.R. Stanton 1990

R.J. Baker, Neil O'Sullivan and G.R. Stanton 1991

N. O'Sullivan and G.R. Stanton 1992-1997

Harold A.S. Tarrant and G.R. Stanton 1998-1999

H.A.S. Tarrant and Hugh M. Lindsay 2000-2003

Peter Davis and Elizabeth Minchin 2004-2012

E. Minchin and Arthur Pomeroy 2013-2014

A. Pomeroy and Han Baltussen 2015-present 